\title{
The Healing Power of Touch: The Specificity of the 'Unspecific' Effects of Massage
}

\author{
Frauke Musial $^{\mathrm{a}}$ Thomas Weiss $^{\mathrm{b}}$

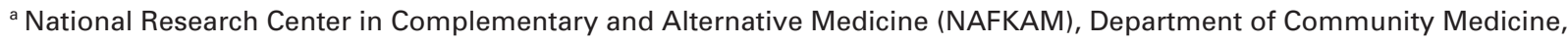 \\ UiT The Arctic University of Norway, Troms $\varnothing$, Norway \\ ${ }^{\mathrm{b}}$ Department of Biological and Clinical Psychology, Friedrich Schiller University of Jena, Germany
}

A recently published, outstanding review by Francis McGlone and colleagues [1] published in Neuron sheds new light on the potential biological mechanisms for the relaxing and anxiolytic effects of massage therapy and related techniques. The authors describe a distinct C-fibre system, which is specific for the entity of pleasant touch.

The reported findings are actually not entirely new. It has long been known from animal studies, that low threshold mechanosensory C-fibres are common in the hairy skin. C-fibres in humans (and animals) are mostly known to be involved in the perception of temperature or, if they have a high threshold, in the perception of pain, and here in particular its affective dimension. However, most investigations of the skin receptors in humans have been conducted in the so-called glabrous skin, which is the skin of the palms of the hands, the sole of the feet, and partly the face. The sensory aspects of the cutaneous innervation of these body parts are mostly related to the perception of the 4 somatosensory submodalities of pressure/vibration, temperature, itch, and pain. These modalities constitute a first 'rapid' touch system, which is highly relevant for discriminative and sensory functions and linked to motor control. However, over the last years evidence has accumulated that humans as well as animals possess tactile low threshold C-fibres (CTs) which are sensitive to gentle touch and form a second touch system, which includes pleasant touch as a modality and represents the neurobiological substrate for the positive hedonic aspects of gentle touch [1].

What is the appropriate stimulus to excite CTs? Basically low velocity stroking movements such as gentle brushing, but also a light poke or stimuli similar to a breeze evoke CTs [2]. Specific to the CT system is that the appropriate stimuli that activate CTs are electrophysiologically correlated with subjective pleasure ratings [3]. Interestingly, massage therapy, which is by most of us considered to be a rather pleasant intervention, utilizes in the broadest sense many of these appropriate stimuli.
Signals from CTs are preprocessed to a very large extend in the spinal cord, before the information is further transmitted to the brain via the spinothalamic tract. At brain level, the main target for the processing of these CT-mediated pleasant properties of touch is the insular cortex [1]. The insula is a structure, which plays a very important role in the processing of emotions [4] and is considered to be the gateway from the sensory systems to the emotional systems of the brain. It is, furthermore, the brain structure central for interoception. Thus, the CT system is likely to induce the autonomic responses associated with pleasant touch such as in relaxation. McGlone and colleagues [1] go even a step further in that they interpret the fact that pleasant touch from hairy skin is processed in limbic structures as a characteristic of an innate nonlearned process.

Until recently, the affective role of touch in humans has been underestimated in neuroscience, while is has been acknowledged in the field of CAM as a favorable active component of many manipulative treatments, especially massage and related techniques. Furthermore, for humans as social animals, the social bond plays an indispensable role for well-being and health [5-7]. Interestingly enough, social bonding and pleasant social interaction are associated with the endogenous release of peptides, such as endorphins, which act directly on the intrinsic opiate system, and oxytocin, which interacts strongly with the endogenous opiate system $[8,9]$.

Holding hands significantly reduced the neural response to threat (experimental pain) in an fMRI paradigm, even when the person holding the hand was a complete stranger [10]. Moreover the effect was strongest, when holding the hand of a beloved spouse. Physical contact and often a soothing touch are indispensable components of many complementary and alternative healing settings as is the observation, that many patients experience the consultation/intervention as relaxing and comforting. This has often been described as the 'unspecific'

\section{KARGER}

Fax +4976145207 14

Information@Karger.com

www.karger.com (c) 2014 S. Karger GmbH, Freiburg

1661-4119/14/0215-0282\$39.50/0

Accessible online at:

www.karger.com/fok
Frauke Musial, PhD

National Research Center in Complementary and Alternative Medicine (NAFKAM)

Department of Community Medicine

UiT The Arctic University of Norway

9037 Troms $\varnothing$, Norway

frauke.musial@uit.no 
effects of these particular treatment settings, indicating that the treatment effects are mainly psychological in nature and independent from the form of treatment delivered. From a neurobiological perspective, the expectation that there is such a phenomenon as a 'specific' effect at brain level is principally questionable and reminiscent of the almost ancient theory of phrenology, where certain functions were localized in precisely defined brain areas. To date, we know that most brain functions are realized by the activity of neural networks where, at the same time, a single structure of a network may be part of several distinct networks. Therefore, it is in fact possible to localize a lesion, but not a function. This questions the assumption, that brain structures are specific in their function.

But why is then the CT system so exciting? Because it identifies a neurobiological substrate explaining many of the mas- sage related effects, that are not directly related to symptom relief (e.g., pain relief). The pathway identified reaches brain structures that are involved in many emotion-related functional contexts, which fits well with the observation that these therapies often induce strong emotions or feelings in patients. McGlone and colleagues [1] argue very conclusively in their 'affective touch hypothesis' that the CT system is the neuronal basis for positive emotions and the experience of pleasure through touch. This conclusion, however, has fundamental consequences for the interpretation of the so-called unspecific effects of massage and related therapies: These effects are specific to the intervention, they have defined health benefits, and they build upon the fundamental and evolutionary determined need of the human primate for skin-to-skin contact with conspecifics!

\section{References}

1 McGlone F, Wessberg J, Olausson H: Discriminative and affective touch: sensing and feeling. Neuron 2014;82:737-755.

2 Abraira VE, Ginty DD: The sensory neurons of touch. Neuron 2013;79:618-639.

3 Essick GK, McGlone F, Dancer C, Fabricant D, Ragin Y, Phillips N, Jones T, Guest S: Quantitative assessment of pleasant touch. Neurosci Biobehav Rev 2010;34:192-203.

4 Craig AD: Interoception and emotion; in Lewis M Haviland-Jones JM, Barrett LF (eds): Handbook of Emotions, ed 3. New York, Guilford, 2008, pp 272 288.
5 House JS, Landis KR, Umberson D: Social relationships and health. Science 1988;241:540-545.

6 Diamond LM: Contributions of psychophysiology to research on adult attachment: review and recommendations. Pers Soc Psychol Rev 2001;5:276-296.

7 Berscheid E: The human's greatest strength: other humans; in Staudinger UM (ed): A Psychology of Human Strengths: Fundamental Questions and Future Directions for a Positive Psychology. Washington D.C., American Psychological Association, 2003, pp 37-47.
8 Uvnaes-Moberg K: Oxytocin may mediate the benefits of positive social interaction and emotions. Psychoneuroendocrinology 1998;23:819-835.

9 Panksepp J: Affective Neuroscience: The Foundations of Human and Animal Emotions. New York, Oxford University Press, 1998.

10 Coan JA, Schaefer HS, Davidson RJ: Lending a hand. Social regulation of the neural response to threat. Psychol Sci 2006;12:1032-1039. 